\title{
Abriendo Puertas Hacia el Futuro: The Road Toward Becoming an Educator
}

Author: Ivonne J. Solano

Faculty Mentor: Mariela Nuñez-Janes, Department of Anthropology, College of Public Affairs and Community Service

Department: Department of Anthropology, College of Public Affairs and Community Service, Ronald E. McNair Post-Baccalaureate Research Program 


\section{Bio:}

Ivonne J. Solano is currently completing a dual degree in psychology and anthropology. Solano has been a member of the Ronald E. McNair post-baccalaureate program where she has been conducting research on bilingual education as a factor influencing the decision to attend college. Solano has presented her research at the sixth, seventh, and eighth annual McNair Research conferences at the University of North Texas and the eleventh annual McNair conference in Buffalo, New York. She is currently a member of Psi Chi. Her current research emphasizes the role of bilingual education as a factor in an individual's choice of attending a university. Her long-term goals are to pursue a doctoral degree in education and teach at the university level. 

3

\begin{abstract}
:
The Oral History Project offers an inside perspective to the Latina/o professors currently at the University of North Texas. This project gave students the opportunity to learn about the educational, personal, and professional trajectory of these professors and will acquaint the UNT community with the diverse experiences and perspectives of professors. Dr. Molina acts as a bridge between teachers-to-be and the diverse population of students with whom they will be working. By balancing all aspects of her life, she was capable of achieving what others would consider an impossible task. Dr. Molina emphasized the importance of choice, and how her choices shaped the path that led her to where she is today.
\end{abstract}




\section{Introduction}

The experience of Dr. Molina illustrates what Gloria Anzaldua describes when two cultures collide and the ability and responsibility to create a unique universe, where one incorporates strengths so one can accomplish as much as possible:

I am a wind-swayed bridge, a crossroads inhabited by whirlwinds...this task - to be a bridge, to be crossroads for goddess' sake...the pull between what is and what should be...the mixture of bloods and affinities, rather than confusing, or unbalancing me, has forced me to achieve a kind of equilibrium (Sanchez, 2002, p. 55).

Gloria Anzaldua is a feminist writer who has brought a voice to women of color and gay women of color. In her work, Anzaldua talks about a cultural collision that leads Latina women in the United States to find their identity and where they belong, adapting endlessly to the many roles required by society. Dr. Molina acts as a bridge for teachers-to-be and for the diverse population of students with whom they will be working. By balancing all aspects of her life, she was capable of achieving what others would consider an impossible task. Dr. Molina emphasized the importance of choice, and how her choices shaped the path that led her to where she is today.

Dr. Molina's narrative about her educational experiences demonstrates how her role as an educator is shaped by her own successes and hardships she encountered while growing up. From the first day she found out she did not understand English to her father telling her to go to college, Dr. Molina was capable of making the best of each experience, not knowing that her path would take her to teach others how to teach, implementing and emphasizing cultural sensitivity in the curriculum. Latinos in the United States are oftentimes required to reconstruct their circumstances in order to have the ability to create their own journey into education and, in Dr. Molina's case, to utilize them in order to make a difference in the experiences of others. 


\section{Childhood Experiences with Racism and Discrimination}

Dr. Molina was born in the Texas Panhandle in the city of Lockney, a small town of around 1,500 people. She was raised in Plainview, Texas and was the second oldest of five siblings. She grew up speaking Spanish, even though both her parents were bilingual. Dr. Molina states, "We spoke Spanish at home, and I think it's just because when you're at home you just talk what you know, what's natural." In many families who reside in the United States, Spanish becomes a means to communicate at home, with family, thus making communication more private and intimate. English is oftentimes used in public matters: in school, at work, and when dealing with individuals outside the familial infrastructure. In Dr. Molina's family, even though both of her parents were fully bilingual, the language spoken at home was Spanish. This environment provided a context for Dr. Molina's education. The first challenge was to learn English.

During the time when she was growing up, the distinctions between Anglos, Hispanics, and African Americans were very prominent and she remembers segregation existing in her elementary school. There were experiences in Dr. Molina's early life that exposed her to racism and discrimination. Today, these past experiences indirectly or directly influence how she undertakes her job. Dr. Molina remembers two instances when she experienced racism and discrimination. The first instance was while she was filling out a census form at school:

I don't know if it was a census or what, in the sixth grade, and I remember the teacher asking me, you know, my ethnicity, or no, we had to fill these forms out, and I came to the ethnicity part, and it said "White/Other," I think that's what it said, or "White/Black." Yeah I think that's what it said. So I went up there, and I said I didn't know which one to fill in, and he (the teacher) pointed to white.

In the Latino culture, there has been an ongoing debate regarding the terms to best describe this group, and also how individuals decide to identify themselves. The time between 
early and late adolescence is a pivotal period in the development of an individual's ethnic identity. When teenagers are exposed to a culture other than their own, this becomes a more crucial period because many questions regarding their identity arise either at home or at school, and children learn to identify themselves by what sets them apart or makes them "different" in society.

The second experience that Dr. Molina spoke about is how, after attending an end-of-year party hosted at a skating rink, she experienced discrimination because she spoke Spanish:

...we went home, and we told mom we wanted to go skating again; and so one Saturday on her way to work she dropped us off, and she started work at one, so she dropped us off early. And she went on to work, and she'd be back to pick us up at six. Well, we waited, it was real hot and we went and sat in the shade, there aren't a lot of trees over there, so on the side of the building and then finally it was time to open, and we were the first ones in line, and we're all in elementary school, and we go up and we're ready to pay, and the man looks down at us and says, "You can't come in 'cause you're Spanish."

Experiencing overt discrimination can affect individuals in many ways, especially if it happens at an early age. Although Dr. Molina experienced negative events while growing up, she had the courage to continue her education, and ultimately became a professor at the University of North Texas. The road to success was not an easy one, yet with determination and by taking advantage of doors that would open on the way, she turned those negative experiences into positive ones and balanced her life in order to succeed. In her professional life, being a professor has given her the chance to not only turn her negative experiences into positive ones, but it has also provided her the opportunity to alter her students' experiences by including cultural sensitivity in the curriculum she teaches.

For students who are trying to become teachers, the question arises as to which type of techniques will address the diversity present in the classroom. Through the use of children's literature, Dr. Molina focuses on adding emotional relevance to the material for both students 
and teachers. An example is the following quote from Harvesting Hope by Kathleen Krull, a book that is used to teach children about Cesar Chavez. It also provides teachers with ways to look outside the box in order to more effectively teach about diversity:

Cesar swallowed his bitter homesickness and worked alongside his family. We were small and not very strong, but still fierce workers. Nearly every crop caused torment, yanking out beets broke the skin between his thumb and index finger.... grapevines sprayed with bug-killing chemicals made his eyes sting and his lungs wheeze. Lettuce had to be the worst.... [It] would make hot spasms shoot through his back. Farm chores on someone else's farm instead of his own felt like horrible slavery (Krull, 2003, p. 14).

As Dr. Molina expressively reads out loud, the listener is immediately transported to the

scene, and one does not only learn about diversity, but also obtains a glimpse of what it would be like if one experienced it. With her explanation, she describes her approach:

...I do try to share a little about my background because I want the students to be aware...you know, of going into teaching, be sensitive to students and the kids' backgrounds ...that they have... and see another perspective and so... I try to share a little bit of my background.... I bring too much of culture and I feel like some students just say ... "I'm going to be a teacher. I know how to teach." You know they don't want so much of the culture, and I think it is just because they can't relate because they haven't ... had those experiences.

\section{Bilingual Education}

In different educational settings, it is imperative that students in various learning environments are exposed to ways of teaching diverse populations. It is necessary for these teachers to recognize that there are differences in the experiences of each student and how that will affect their education experiences. Luis C. Moll and Richard Ruiz's (2002) idea of "educational sovereignty" is represented in the approach that Dr. Molina teaches to her students who are preparing for careers in teaching. Educational sovereignty means that communities create their own infrastructures for development, including mechanisms for the education of their children that capitalize on rather that devalue their cultural resources. What this allows them to do is to utilize the resources present in their culture in order to succeed. 
One of the issues that has been debated over the years is bilingual education. These programs were not in existence when Dr. Molina attended school, but instead of seeing it as a disadvantage, she chose to be involved in bilingual education throughout her post-baccalaureate education. Because she did not know English when she started school, Dr. Molina had to attend summer school in El Barrio, which she describes as, "a certain part of town where minorities live." She relates the instance when she found out she did not know English:

I remember going there, and the teacher at the beginning would take the count how many would want to buy milk at the break, because it was just a half-day program. And I remember, she would go down the row, and then she would come to me and I would just shake my head, 'cause I didn't have three cents for milk. And she would say, I don't remember how she would say it, but I remember her doing this. And I would just say 'no,' and she would always write me down for milk. So I didn't know if she was paying for it, but that's what I remember that I didn't understand English.

Dr. Molina succeeded in her education; she was capable of balancing her personal life and continued with her education in order to provide her children with better opportunities. It was at Lamar College that she joined a club and met a professor of languages who was the first professor that she knew on a personal level. Because her major was not clear, she thought about majoring in languages until one of her friends mentioned the bilingual education program. She assessed her strengths (working with children, her ability in languages), and this was what led her to pursue her three degrees in bilingual education.

Because she had three children, her experiences in graduate school were different because wherever she moved, she needed to also find the best environment for her children. Throughout her career, she has observed the differences among educational settings that are present in the schools where she sent her kids and where she worked. By using the allegory of "on the other side of the tracks," she illustrates the "barrioization," as Velez-Ibañez (1996) calls it, and how educational ideologies are altered by the way of living. If we stop and observe the 
way that various minorities live today, still in barrios, below the "political line," on the "other side of the tracks" (Velez-Ibañez, 1996), we can observe that even in present-day America, the educational experiences and quality of education are very different depending on the location of residence.

\section{Conclusion}

Dr. Molina enjoys her position at UNT because being a visiting professor allows her to focus on teaching. One of the aspects that she would like to improve on is research. Although she considers her degrees accomplishments, she says, "I still have more to go if I'm going to be a professor or be involved with scholarship..." Although Dr. Molina enjoys her ability to focus on students and teaching, she also wants to focus more on scholarship and research. Being a professor includes the responsibility to better herself, and to never stop learning. Furthermore, it is the duty of a professor to contribute to the improvement of his or her field-in this case, education. 


\section{References}

Krull, K. (2003). Harvesting hope: The story of Cesar Chavez. San Diego, CA: Harcourt Children's Books.

Moll, L. C., \& Ruiz, R. (2002). The schooling of Latino children. In M. M. Suárez-Orozco \& M. M. Páez (Eds.), Latinos: Remaking America (pp. 362-374). Berkeley: University of California Press.

Sanchez, G. J. (2002). "Y tu, que?": Latino history in the new millennium. In M. M. SuárezOrozco \& M. M. Páez (Eds.), Latinos: Remaking America (pp. 45-58). Berkeley: University of California Press.

Velez-Ibanez, C. G. (1996). The American entrada, "barrioization" and the development of Mexican commodity identity. In C. G. Velez-Ibanez (Ed.), Border visions: Mexican cultures of the Southwest United States (pp. 57-88). Tucson: University of Arizona Press. 